\title{
GAMBARAN PENGGUNAAN BAHAN TUMPATAN DI POLIKLINIK GIGI PUSKESMAS KOTA BITUNG TAHUN 2014
}

\author{
${ }^{1}$ Catra H. E. Lengkey \\ ${ }^{2}$ Ni Wayan Mariati \\ ${ }^{2}$ Damajanty H. C. Pangemanan \\ ${ }^{1}$ Kandidat Skripsi Program Studi Pendidikan Dokter Gigi Fakultas Kedokteran \\ ${ }^{2}$ Program Studi Pendidikan Dokter Gigi Universitas Sam Ratulangi \\ E-mail: catra.lengkey@gmail.com
}

\begin{abstract}
Health is an important thing for every human being and caries is a health problem that damaging email and dentin structure of teeth. The solution to that case is to clogged up the damaged teeth. The purpose from this research is to describe theuse of clogged up materials in dental clinic over all health centers clinic in Bitung city in 2014.This research use descriptive retrospective design. The research sample is the entire patient medical record of patients with clogged up materials in all health centers of Bitung city that uses total sampling method during 2014. Total sampel that obtained are 27 sampel and categorized based on age, sex, and teeth region. The most used clogged up material during 2014 is GIC filling, age category that ranged from 26-55 years old are received most of clogged up treatment and female patients are the most who receive this treatment. Anterior teeth region is the most region teeth that receive composite clogged up and GIC in posterior region
\end{abstract}

Keywords: clogged up material, composit, GIC

\begin{abstract}
Abstrak:Kesehatan merupakan hal yang penting bagi setiap manusia dan karies merupakan salah satu masalah kesehatan yang merusak struktur email dan dentin dari gigi dan penanggulangannya adalah dengan menumpat gigi yang mengalami kerusakan. Tujuan dari penelitian yaitu untuk mengetahui gambaran penggunaan bahan tumpatan di poliklinik gigi seluruh puskesmas yang ada di Kota Bitung pada tahun 2014. Penelitian menggunakan disain deskriptif dengan pendekatan retrospektif. Sampel penelitian ialah seluruh rekam medik pasien pengguna bahan tumpatan di seluruh puskesmas kota Bitung yang menggunakan metode total sampling selama 2014. Total sampel yang didapatkan 27 sampel dan dikategorikan berdasarkan umur, jenis kelamin dan regio gigi. Tumpatan yang paling banyak dipakai tahun 2014 adalah tumpatan GIC, kategori umur 26-55 tahun yang paling banyak menerima penumpatan, pasien perempuan paling banyak menerima perwatan tumpatan, regio gigi anterior paling banyak menerima tumpatan komposit dan posterior GIC.
\end{abstract}

Kata kunci: bahan tumpatan, komposit, GIC.

Kesehatan merupakan hal yang sangat penting bagi setiap manusia untuk dapat melakukan berbagai aktivitas baik secara fisik, mental dan kesejahtraan sosial secara keseluruhan. Tujuan diselenggarakan pembangunan kesehatan ialah meningkatkan kesadaran, kemauan, dan kemampuan hidup sehat bagi semua orang agar terwujud derajat kesehatan yang optimal. Sampai saat ini masalah kesehatan gigi yang banyak ditemukan yaitu karies gigi.

Karies ialah suatu penyakit infeksi yang merusak struktur gigi seperti email, dentin dan sementum berupa demineralisasi 
pada struktur gigi yang kemudian diikuti oleh kerusakaan bahan organiknya. Berdasarkan Data Riset Kesehatan Dasar (RISKESDAS) 2013 indeks DMF-T di provinsi Sulawesi Utara sebesar 5,4 dengan nilai masing-masing $\mathrm{D}-\mathrm{T}=1,9, \mathrm{M}-\mathrm{T}=3,4$, $\mathrm{F}-\mathrm{T}=0,06{ }^{1}$

Salah satu upaya penanggulangan karies ialah dengan melakukan penumpatan sebagai upaya konservatif. Penumpatan gigi merupakan suatu tindakan restorasi gigi dengan cara membuang jaringan karies dan meletakan bahan restorasi pada gigi yang mengalami kerusakan. Tindakan perawatan menggunakan bahan restorasi lebih efektif dibandingkan dengan pencabutan karena pertimbangan estetika dan fungsional. Hal ini membuat pasien dan dokter gigi mempunyai banyak pilihan yang bervariasi dalam memilih jenis bahan material untuk merestorasi struktur gigi yang mengalami kerusakan. ${ }^{2}$

Jenis bahan restorasi yang sering digunakan dalam bidang kedokteran gigi ialah resin komposit, semen ionomer kaca (SIK) dan amalgam. Sebagai bahan restorasi tentunya masing-masing memiliki kelebihan dan kekurangan. Kelebihan dari bahan tumpatan komposit dalam penggunaanya ialah dari segi estetik paling baik dan sewarna dengan gigi, sifat mekanik dan fisik cukup baik, dapat digunakan di gigi posterior, tidak mengandung merkuri, sementara itu resin komposit memiliki kekurangan iritatif terhadap pulpa, dari segi biaya relatif mahal, dapat terjadi karies sekunder dibawah tumpatan, dapat berubah warna dalam pemakaian jangka panjang, keausan permukaan oklusal dan terjadi pengerutan saat polimerisasi. ${ }^{3,4,5,6,7}$ Sementara itu SIK memiliki beberapa keuntungan yaitu melekat secara fisika kimia dengan jaringan gigi, mengandung fluor, melepaskan fluor, tidak mengiritasi jaringan mulut dan gingiva, bersifat bakteriostatik, dan berfungsi sebagai reservoir fluor selama tumpatan berada di mulut dan dalam keadaan baik. ${ }^{8}$ dibalik semua keuntungan
SIK terdapat juga kekurangan yaitu tidak dapat menerima tekanan kunyah yang besar, mudah abrasi dan erosi, dan translusent-nya lebih rendah. ${ }^{9}$ Amalgam memiliki kelebihan kuat dan tahan lama, tahan terhadap tekanan kunyah, harganya paling murah diantara bahan resotrasi yang lain, resiko terjadinya kebocoran sangat kecil, dapat digunakaan pada suasana lembab, dan amalgam memiliki kekurangan menyebabkan perubahan warna pada gigi karena bersifat korosi, membutuhkan banyak pengambilan jaringan gigi yang sehat, menimbulkan alergi pada beberapa pasien berupa inflamasi dan gatal, mengandung merkuri yang berbahaya. ${ }^{10}$

Salah satu kota yang ada di wilayah provinsi Sulawesi Utara ialah kota Bitung. Kota Bitung ialah kota dengan tingkatan kotamadya, dengan memiliki 8 kecamatan, dari 8 kecamatan terdapat 9 puskesmas yang tersebar diseluruh kota Bitung. Kota Bitung termasuk kota yang sedang berkembang dari segi ekonomi dan sosial. Kota Bitung merupakan kota industri, hal ini dibuktikan dengan adanya berbagai macam tempat industri yang ada dikota Bitung.

Penelitian ini bertujuan untuk mengetahui penggunaan bahan tumpatan di Poliklinik Gigi seluruh puskesmas yang ada di kota Bitung.

\section{METODE PENELITIAN}

Penelitian ini merupakan penelitian deskriptif survei. Penelitian ini dilaksanakan pada bulan juni 2015 di seluruh puskesmas kota Bitung. Metode pengambilan sampel yang digunakan metode total sampling yaitu suatu pengambilan sampel yang dilakukan dengan cara memakai seluruh populasi dalam pelaksanaan penelitian yang berjumlah 27 sampel dan sesuai kriteria inklusi. Variabel penelitian ini yaitu bahan tumpatan dan rekam medik. Pengambilan data sampel diambil dari seluruh rekam medik pengguna bahan tumpatan yang ada di seluruh puskesmas kota Bitung. Data 
yang diperoleh dalam penelitian ini dikumpulkan dan diolah menggunakan komputer dengan program microsoft excel 2007. Analisis data menggunakan analisis univariat yang disajikan dalam bentuk tabel.

\section{HASIL PENELITIAN}

Penelitian dilaksanakan diseluruh puskesmas kota Bitung dengan jumlah sampel penelitian 27 sampel. Hasil penelitian mengenai penggunaan komposit, GIC, dan amalgam berdasarkan umur, jenis kelamin, dan regio gigi.

Tabel 1. Distribusi frekuensi bahan tumpatan berdasarakan umur

\begin{tabular}{ccccccc}
\hline \multirow{2}{*}{ Kategori } & \multicolumn{2}{c}{ Komposit } & \multicolumn{2}{c}{ GIC } & \multicolumn{2}{c}{ Amalgam } \\
\cline { 2 - 7 } & $\mathrm{n}$ & $\%$ & $\mathrm{n}$ & $\%$ & $\mathrm{n}$ & $\%$ \\
\hline Anak- & 0 & 0 & 0 & 0 & 0 & 0 \\
anak & & & & & & \\
Remaja & 4 & 31 & 4 & 29 & 0 & 0 \\
Dewasa & 9 & 69 & 9 & 64 & 0 & 0 \\
Lansia & 0 & 0 & 1 & 7 & 0 & 0 \\
Total & 13 & 100 & 14 & 100 & 0 & 0 \\
\hline
\end{tabular}

Tabel 2. Distribusi frekuensi bahan tumpatan berdasarkan jenis kelamin

\begin{tabular}{ccccccc}
\hline \multirow{2}{*}{ Kategori } & \multicolumn{2}{c}{ Komposit } & \multicolumn{2}{c}{ GIC } & \multicolumn{2}{c}{ Amalgam } \\
\cline { 2 - 7 } & $\mathrm{n}$ & $\%$ & $\mathrm{n}$ & $\%$ & $\mathrm{n}$ & $\%$ \\
\hline $\mathrm{L}$ & 4 & 31 & 6 & 43 & 0 & 0 \\
$\mathrm{P}$ & 9 & 69 & 8 & 57 & 0 & 0 \\
Total & 13 & 100 & 14 & 100 & 0 & 0 \\
\hline
\end{tabular}

Tabel 3. Distribusi frekuensi bahan tumpatan berdasarkan regio gigi

\begin{tabular}{ccccccc}
\hline \multirow{2}{*}{ Kategori } & \multicolumn{2}{c}{ Komposit } & \multicolumn{2}{c}{ GIC } & \multicolumn{2}{c}{ Amalgam } \\
\cline { 2 - 7 } & $\mathrm{n}$ & $\%$ & $\mathrm{n}$ & $\%$ & $\mathrm{n}$ & $\%$ \\
\hline $\begin{array}{c}\text { Anterior } \\
\text { Atas }\end{array}$ & 10 & 77 & 1 & 7 & 0 & 0 \\
$\begin{array}{c}\text { Anterior } \\
\text { Bawah }\end{array}$ & 0 & 0 & 0 & 0 & 0 & 0 \\
$\begin{array}{c}\text { Posterior } \\
\text { Atas }\end{array}$ & 2 & 15 & 6 & 43 & 0 & 0 \\
$\begin{array}{c}\text { Posterior } \\
\text { Bawah }\end{array}$ & 1 & 8 & 7 & 50 & 0 & 0 \\
Total & 13 & 100 & 14 & 100 & 0 & 0 \\
\hline
\end{tabular}

\section{BAHASAN}

Penggunaan Komposit, Glass Ionomer Cement, dan Amalgam Berdasarkan Umur

Berdasarkan kelompok usia, kelompok usia 26-55 tahun merupakan usia yang paling banyak menggunakan bahan tumpatan, dengan komposit sebesar 9 orang (69\%), dan GIC sebesar 9 orang (64\%), Hal ini serupa dengan penelitian sebelumnya yang dilakukan di RSGMP FKG UI selama 3 tahun oleh Indriani tentang survei pemaparan amalgam, GIC, dan resin komposit sebagai bahan tumpat gigi, yang menurut Indiriani karena usia dewasa merupakan usia produktif yang telah memiliki pengetahuan dan kesadaran diri yang tinggi terhadap segi estetika dan fungsional dari kesehatan gigi dan mulut dibandingkan kelompok usia lainnya. ${ }^{3}$

Kelompok usia dewasa sekarang ini memiliki pola hidup yang bervariasi. Hal ini dapat dilihat dari meningkatnya kebisaan mengkonsumsi makanan dan minuman yang mengandung asam. Zat asam yang terkandung dalam makanan dan minuman ringan merupakan faktor utama penyebab Terjadinya demineralisasi pada jaringan keras seperti karies dan erosi. ${ }^{11}$ Jika gigi sudah mengalami kerusakan kelompok usia dewasa akan segera melakukan tindakan perawatan penumpatan karena pada kelompok usia dewasa tingkat pengetahuan dan kesadaran diri terhadap nilai estetika dan fungsi gigi dalam ronga mulut lebih tinggi dibandingkan dengan kelompok usia lainnya. ${ }^{9}$

\section{Penggunaan Komposit, Glass Ionomer Cement, dan Amalgam Berdasarkan Jenis Kelamin}

Berdasarkan jenis kelamin bahwa tabel 3 menunjukkan pasien berjenis kelamin perempuan paling banyak menerima perawatan tumpatan dengan komposit 9 orang (69\%) dan GIC 8 orang (57\%). Hal ini sejalan dengan penelitian yang dilakukan di poli gigi RS. Gunung Maria Tomohon tahun 2012 oleh Sumolang 
hasilnya menunjukkan bahwa perempuan paling banyak menerima perawatan bahan tumpatan. $^{2}$

Berdasarkan asumsi kaum perempuan sangat memperhatikan kesehatan terutama penampilan, dan salah satunya penampilan estetik gigi geligi yang sangat menunjang penampilan kaum perempuan.

Pada saat pubertas, menstruasi, kehamilan dan menopause dapat terjadi perubahan pada rongga mulut. ${ }^{12}$ Karena proses kehamilan merupakan salah satu faktor penyebab perubahan pada rongga mulut, akibatnya wanita cenderung beresiko mengalami gangguan kesehatan gigi dan mulut. Hal yang menyebabkannya yaitu memper-cepatnya proses karies yang sudah ada pada masa kehamilan karena perubahan $\mathrm{pH}$ saliva, pada wanita hamil $\mathrm{pH}$ saliva lebih asam jika dibandingkan dengan wanita tidak hamil. $\mathrm{pH}$ yang asam diakibatkan rasa mual dan muntah pada wanita hamil, dan sewaktu hamil wanita biasanya sering mengkonsumsi makananmakanan yang mengandung gula dan malas memelihara kebersihan rongga mulutnya. ${ }^{3}$ Karena kebiasaan wanita saat hamil cenderung malas menjaga kesehatan gigi dan mulut sehingga mereka berisiko mengalami gangguan kesehatan gigi dan mulut. ${ }^{13}$ Pasien perempuan memiliki gigi yang rusak akibat karies dapat memberikan rasa tidak nyaman dan kurang percaya diri, sehingga perempuan biasanya segera memeriksakan giginya ke dokter gigi untuk mendapatkan perawatan tumpatan pada gigi yang mengalami karies. ${ }^{14}$

\section{Penggunaan Komposit, Glass Ionomer Cement, dan Amalgam Berdasarkan Regio Gigi}

Berdasarkan regio gigi, bahan tumpatan yang paling sering dipakai adalah jenis bahan tumpatan GIC pada regio posterior atas maupun bawah yaitu sebanyak 13 orang (93\%) dan 1 orang (7\%) pada regio anterior dibandingkan dengan tumpatan komposit. Pada regio posterior tumpatan GIC banyak digunakan karena bahan ini dari sifatnya yang estetis, tidak iritatif terhadap pulpa, mengandung fluor, dan segi ekonomi mudah dijangkau oleh masyarakat walaupun masyarakat tidak mengetahui seberapa kuat bahan tumpatan ini menerima tekanan. Hal ini sejalan dengan penelitian yang dilakukan Saerang di Rumah Sakit Gigi dan Mulut Universitas Sam Ratulangi Manado pada tahun 20112012 tentang penggunaan semen ionomer kaca sebagai bahan tumpatan gigi, dimana permukaan gigi posterior sering ditemukan adanya karies karena dari segi morfologi adanya pit dan fisur, yang merupakan daerah ideal untuk terjadinya retensi sisa makanan dan bakteri penyebab karies. ${ }^{15}$

Pada penelitian ini penggunaan tumpatan komposit banyak dipakai pada regio anterior yaitu sebanyak 10 orang (77\%) dan hanya 3 orang (23\%) pada regio posterior. Hal ini dikarenakan dari segi estetiknya bahan tumpatan komposit lebih baik dibandingkan bahan tumpatan yang lain karena salah satu kelebihan dari bahan tumpatan komposit ialah sewarna dengan gigi, dan dari segi ekonomi bahan tumpatan komposit lebih mahal dari tumpatan yang lain sehingga pemakaian bahan tumpatan komposit lebih sedikit dibandingkan bahan tumpatan GIC sebab persediaan bahan tumpatan komposit sangat terbatas karena penyedia bahan tumpatan ini ialah hanya dari swadaya pihak poliklinik Gigi Puskesmas dan belum pernah mendapatkan bantuan dari pemerintah.

Bahan tumpatan amalgam sudah tidak dilakukan karena tidak tersedianya bahan tumpatan ini di puskesmas. Salah satu kekurangan amalgam selain harus mengambil jaringan gigi yang lebih banyak, amalgam juga menghasilkan restorasi yang kurang estetis, sehingga bahan tumpatan amalgam sudah tidak digunakan lagi.

\section{SIMPULAN}

Berdasarkan penelitian yang telah dilakukan di seluruh puskesmas yang ada di kota Bitung tahun 2014 dapat 
disimpulkan penggunaan bahan tumpatan paling banyak ialah tumpatan GIC, kategori umur 26-55 tahun merupakan kelompok umur dewasa yang sering melakukan penumpatan (67\%) dan pasien perempuan paling sering menerima tumpatan komposit dibandingkan tumpatan GIC dan amalgam. Regio gigi anterior paling banyak dilakukan tumpatan komposit sedangkan pada regio posterior tumpatan GIC.

\section{SARAN}

1. Bagi pemerintah kota Bitung khususnya dinas kesehatan kota Bitung Perlu dilakukan peningkatan terhadap mutu pelayanan kesehatan di beberapa daerah puskesmas kota Bitung.

2. Perlu dilakukan penelitian lebih lanjut agar dapat diperoleh data statistik yang lebih dan dapat dijadikan data pembanding terhadap hasil penelitian ini.

\section{UCAPAN TERIMA KASIH}

Ucapan terima kasih disampaikan pada drg. Christy Mintjelungan M.Kes dan drg. P.S. Anindita Sp.Orto, serta semua pihak yang baik secara langsung telah menumbuhkan ide atau gagasan dalam pemikiran penulisan sehingga dapat menyelesaikan artikel ini

\section{DAFTAR PUSTAKA}

1. Dental board of california(editorial).CA Sacramento. 2005;5; p.04

2. Satish C, Chandra S, Girish C. Textbook of operative dentistry. New delhi:2007.p.236-247

3. Strassler HE, Predictable restoration of posterior teeth with composite resin. University of Maryland Dental School;2009;p.98-104

4. Agtini MD. Efetifitas pencegahaan karies dengan Atraumatic Restoratif Treatment dan tumpatan Glass Ionomer Cement dalam pengendalian karies di beberapa negara. Ejournal Litabang. 2010

5. Tulaka B, Wicaksono DA, Tumewu E. Gambaran penggunaan semen ionomer kaca sebagai bahan tumpatan di rumah sakit robert wolter monginsidi. Jurnal E Gigi. 2014

6. Ryan R. Mengenal kelebihan dan kekurangan bahan tambal gigi berlubang. 20 Desember 2012 [Cited 01 September 2015]. Avaible from : http://aspalputih.blogspot.com/2012/12/mengena l-kelebihan-dan-kekuranganbahan.html?m=1

7. Anbrani AG. Prevalence of Enamel Demineralization: A Screening Study using clinical and imaging Tools.2015[Cited 4 Agustus 2015]. Avaible From: https://urop.due.uci.edu/urop/symp/r5 4ew3/4970165491_version1.doc

8. Purwanto TP. Cermati peran estrogen dan androgen pada rongga mulut. 28 November 2011 [cited 25 juli 2015]. Avaible from http://edisicetak.joglosemar.co/berita/ cermati-peran-estrogen-danandrogen-pada-rongga-mulut61522.html

9. Mamentu NC. Gambaran status ginggiva ibu hamil trimester ketiga yang berkunjung dipoli kandungan RSU Budi Mulia Kota Bitung. Skripsi. Manado: Universitas Sam Ratulangi; 2014.p.24

10.Latif F. Gambaran penggunaan tumpatan amalgam sebagai bahan restorasi di poliklinik Gigi RSUP. Prof. Kandou tahun 2008,2009, dan 2010. Skripsi. Manado: Universitas Sam Ratulangi; 2011.p.34.

11.Saerang GS. Gambaran Penggunaan semen ionomer kaca sebagai bahan tumpatan gigi di Balai Pengobatan Rumah Sakit Gigi dan Mulut Universitas Sam Ratulangi pada tahun 2011 sampai 2012. Jurnal E gigi.

12.Riset Kesehatan Dasar. Badan penelitian pengembangan kesehatan Departemen Kesehatan, Republik Indonesia. Jakarta; Laporan Nasional: 2013.p.118.

13.Sumolang M. Gambaran penggunaan resin komposit dan semen ionomer kaca sebagai bahan restorasi di poli gigi rumah sakit Gunung Maria Tomohon 
Lengkey, Mariati, Pangemanan: Gambaran penggunaan bahan...

tahun 2012. Jurnal E Gigi

14.Idriani. Survei pemaparan penggunaan amalgam, GIC, dan resin komposit sebagai bahan tumpat gigi di RSGMP FK UI pada tahun 2005, 2006, dan 2007. Skripsi. Jakarta: Universitas
Indonesia; 2008. p.2.

15.Uba SI. Gambaran penggunaan bahan tumpatan di poliklinik gigi BLU RSUP. Prof .DR.R.D Kandou.Skripsi; 2014.p.9. 